\section{High Pressure Explosive Processing of Ceramics Edited by R.A. Graham and Akira B. Sawaoka}

This book comes as a beacon of potential for new materials development using a rather bizarre fabrication scheme. Dick Spriggs' overview of the book in Chapter 2 provides an essential roadmap for the reader, and the book really cannot be appreciated without first reading this chapter since it provides some essential context. Spriggs concludes, "Commercial products are not yet known from the foregoing shock-enhanced sintering techniques. However, such methods hold considerable promise, and several later chapters of this book are devoted to these processes."

The 12 chapters following Spriggs' introductory remarks present some interesting prospects and proposals.

It is standard practice to develop a book review based on the presumption of content by the reviewer or a summary of the chapter content. This review will deviate from this routine because it is not so much the content of the book that is novel and important as the concept and the context in which it was written. To quote the editors' Preface, "The present book was edited and published to bring together the threads of a wide ranging and significant materials research area which has had limited visibility because publications are widely scattered among a number of sources."

But, the book does more than just bring together threads. It provides some intriguing possibilities for materials modification and synthesis, particularly ceramic materials, using the unique features of the highpressure state. Readers already familiar with ceramic powder processing will be particularly intrigued by the prospects for enhancing conventional processes by subjecting powder to a shock wave prior to processing. It is these fundamental issues which constitute these threads of materials research.
While the book might appeal to anyone interested in novel materials research, it will be particularly rewarding for students and researchers in ceramic science who are not necessarily experts in high-pressure physics. In this context, it may indeed "stimulate and guide future research activities" as the editors conclude in the preface.

The only notable shortcoming of the book is its rather short index, a little disconcerting for a more knowledgeable materials researcher who may want to locate particular topics within the book. But the reviewer looked at the chapters as a kind of sampler rather than a reference resource, and the book is more interesting to browse through than to consider as a more traditional reference book. It is recommended reading for a wide range of materials scientists and engineers.

L.E. Murr is professor of materials science and engineering at the Oregon Graduate Center, the editor of several books dealing with shock-wave phenomena, and the organizer of EXPLOMET, an intermational conference on the effects of shock waves and high-stmin-rate phenomena.

\section{Handbook of Contamination Control of Microelectronics Edited by Donald L. Tolliver . \\ (Noyes Publications, 1988)}

This book is a compilation of 14 individual reviews on various aspects of contamination control for microelectronics. The contents are generally very current, and overall, the book is highly recommended for beginners in this field or for those wishing to pursue references to more detailed work. There are much better books dedicated to the specifics behind individual issues, but this is a good, comprehensive overview of current contamination control issues in the semiconductor industry.

The book is anchored by four excellent chapters on gas filtration technology, instrumentation for aerosol particle detec- tion, DI water filtration technology, and the technology of producing ultrapure gases. Each chapter gives an outstanding review of the state-of-the-art technology, with extensive lists of references to the pertinent literature.

The chapter on aerosol filtration technology, by D. Ensor and R. Donovan, reviews the basic fundamentals of filtration technology with a good summary of the theoretical expressions describing all aspects of filtration. This chapter includes 93 references.

The chapter on instrumentation for aerosol particle detection, by B. Liu and D. Pui, is filled with data on aerosol sampling and calibration and includes 32 references. This chapter is an excellent review of the techniques available for particle detection and size measurement.

The chapter on DI water filtration, by $M$. Accomazzo, G. Gauzi, and R. Kaiser, describes all the issues of filtration of high purity water for microelectronics fabrication and gives 53 references.

G. Kasper and H.Y. Wen, in their chapter on the technology of ultrapure process gases, present an excellent review of the scientific issues of producing clean gases for processing. This chapter lists 35 references.

Other notable chapters cover contamination control issues in lithography, surface particle detection technology, contamination in processing equipment, particle monitoring systems for liquids, and wafer automation and transfer systems for particle control. Each is a fairly good review and provides a reasonable list of references. However, each fails to provide adequate references to more detailed work so an interested reader can get more in-depth information.

As with most books of this type, a few chapters only adequately cover their topics. In this case, five chapters fit this category and cover clean room management, clean room garments and fabrics, electrostatics, chemicals, and issues for ultrapure DI water production. These five chapters fall far short of providing adequate references to other information, but overall the book is an exceptional compilation of review chapters on current contamination control issues in microelectronics.

Reviewer: R. Allen Bowling is mannger, Advanced Thermal and Contamination Control Technology Branch, Semiconductor Process and Design Center, Texas Instruments. His recent research interests are particulate contamination measurement and control in semicondictor processing equipment. 